\section{Acute otitis media}

SIR, $-\mathrm{Mr}$ George G Browning and colleagues state that diagnosing acute otitis media is not easy even when carried out by specialists.' Unfortunately, in two of the studies quoted ${ }^{23}$ the diagnosis was made predominantly by doctors without specialist training. If only half of children with otalgia have acute otitis media some of the figures quoted may be underestimated by a factor of two. Even if the data are accurate, surely a failure of resolution in $15 \%$ of "untreated" children is unacceptably high?

The advocated policy of withholding antibiotics for 24 hours would require the general practitioner to review management at an early stage - two or three consultations within this period would be needed to detect those children who warrant antibiotic treatment. This would be impractical for most general practitioners, and the cost of increased consultations would have to be set against savings made from fewer prescriptions.

Mr Browning and colleagues fail to mention fever, one of the cardinal signs of bacterial sepsisglue ear is not associated with fever. The fever associated with acute otitis media is usually greater than that with viral upper respiratory infections and this sign may help in deciding if antibiotics are indicated.

Finally, it should be remembered that acute otitis media can be complicated by life threatening intracranial sepsis, albeit rarely.

F J LANNIGAN JC WATKINSON $S$ WARD

Guy's Hospital, London SE1 9RT

Browning GG, Bain J, Rubin P. Childhood otalgia: acute otitis media. $B r$ Med f 1990;300:1005-7. (14 April.)

2 Van Buchem FL, Dunk JHM, Van't Hof MA. Therapy of acute otitis media: myringotomy, antibiotics, or neither? Lancet 1981;ii:883-6.

3 Van Buchem FL, Peeters MF, Van't Hof MA. Acute otitis media: a new treatment strategy. Br Med f 1985;290:1033-7.

SIR,-Several comments must be added to Professor John Bain's article' and associated recent correspondence. $^{2}$

Unfortunately, Professor Bain did not justify the use of antibiotics for acute otitis media. It is well recognised that acute otitis media can be managed adequately without the use of antibiotics. ${ }^{3+}$ The British studies by Professor Bain show only that there is no difference between using a course of antibiotics for two to three days and for seven to 10 days. ${ }^{56}$ These findings support our view that antibiotics have no place in the initial treatment of acute otitis media because they have no effect on the long term recurrence of the disease over the succeeding 12 months. Surely a more relevant study would include a further control group with a placebo arm and no antibiotic? Professor Bain assures us that this study is being conducted in the United Kingdom, ${ }^{2}$ yet similar studies have been performed already in other centres in Europe with results that militate against the use of antibiotics.

Palva et al warn that "the liberal use of antibiotics for every earache by general practitioners at health care centres is undoubtedly responsible for masking the signs of acute mastoid disease." This view is shared by Rubin and Wei, who strongly advocate treatment with local and systemic decongestant-treatment that is somewhat deprecated by Professor Bain. In a series of patients with acute suppurative mastoiditis only $5 \%$ had received decongestants, not only to maximise drainage of the middle ear through the eustachian tube but also to decongest the mastoid antral mucosa to allow adequate drainage of the mastoid air cell system into the middle ear. ${ }^{8}$

Professor Bain states that analgesia for the child is often inadequate. ${ }^{5}$ This is where the main controversy lies - adequate analgesia and decongestant treatment are of greater importance than antibiotics in the initial treatment of suspected acute otitis media in childhood. A slightly red tympanic membrane may reflect only vascular congestion caused by crying. The basic surgical principle for the treatment of suppurative infection in a body cavity would normally include surgical drainage-myringotomy. To avoid such a procedure in the early stages of possible acute otitis media, however, local and systemic decongestants with adequate analgesia would seem a more logical treatment.

D W SKINNER A J PRICHARD A NARULA

Leicester Royal Infirmary

Leicester LE1 5 WW

Browning GG, Bain J, Rubin P. Childhood otalgia: acute otitis media. Br Med f 1990;300:1005-7. (14 April)

2 Correspondence. Acute otitis media. Br Med F 1990;300:1341-2. (19 May.)

3 Van Buchem FL, Peeters MF, Van't Hof MA. Acute otitis media: a new treatment strategy. Br Med f 1985;290:1033-7. 4 Mygind N, Meistrup-Larsen KI, Thomsen J, et al. Penicillin in acute otitis media: a double blind placebo controlled trial. Clin Otolaryngol 1981;6:5-13.

5 Jones RH, Bain DJG. Three day and seven day treatment in acute otitis media: a double blind antibiotic trial. $\mathcal{F} R$ Coll Gen Pract 1986;36:356-8.

6 Bain DJG, Murphy E, Ross F. Acute otitis media: clinical course among children who received a short course of high dose antibiotic. Br Med f 1985;291:1243-6.

7 Palva T, Virtanen H, Makinen J. Acute and latent mastoiditis in children. F Laryngol Otol 1985;99:127-36.

8 Rubin JS, Wei WI. Acute mastoiditis: a review of 34 patients. Laryngoscope 1985;95:963-5.

\section{Minitracheotomy}

SIR, - Dr D W Ryan emphasised the usefulness of minitracheotomy in the management of sputum retention.' It was clearly not his brief to discuss the benefits of the technique in patients with acutely obstructed airways but there is plenty of evidence that minitracheotomy may be a satisfactory alternative to formal tracheotomy. Even in inexperienced hands minitracheotomy is potentially life saving and is associated with few serious complications.

Dr Ryan states that the procedure should not be used in patients with a bleeding diathesis or in those who are unable to protect their airway and should be used with considerable caution in those needing high frequency jet ventilation. While nobody would disagree with the first assertion, I think that the subsequent statement is wrong. Minitracheotomy is most useful for bronchial toilet and short term ventilation in patients who are unable to protect their airways, and it is safe and extremely effective with high frequency jet ventilation. ${ }^{2}$ In patients with complete laryngeal disruption any form of positive pressure ventilation is contraindicated, but such cases are rare, and minitracheotomy would merely be a first aid measure before formal exploration.

Bedford General Hospital

M C FRAMPTON Bedford MK42 9DJ

1 Ryan DW. Minitracheotomy. Br Med f 1990;300:958-9. (14 April.)

2 Squires SJ, Frampton MC. The use of minitracheotomy and high frequency jet ventilation in the management of acute airway obstruction. F Laryngol Otol 1986;100:1199-202.

\section{Simulation in surgical training}

SIR, - While we agree with Messrs I M C MacIntyre and $A$ Munro that in many instances training in operative surgery falls short of the ideal, we cannot agree with their radical suggestions.' ${ }^{\prime}$ The logical and correct response is to improve present standards and to stop paying lip service to the concept of training. To use budgetary constraints, hours of work, waiting lists, and the "service first" environment as excuses for removing surgical training from the operating theatre does a dis- service to all those excellent surgeons who have trained junior doctors over the years. To sugges that current surgical practice militates against training junior surgeons in the operating room is nonsense. As surgeons in training (and we are all, after all, surgeons in training) we should resist strongly any attempt to separate trainees from what has previously been their normal place of working.

Messrs MacIntyre and Munro are obviously avid proponents of anastomosis workshops. These courses have a definite but limited role in the training of junior surgeons that should not be overstated. There is a world of difference between a difficult dissection and an anastomosis - in many respects an anastomosis may be relatively simple to perform. Bioengineers and moulding technicians must be resourceful to reproduce some of the technical difficulties encountered occasionally in the abdominal cavity, and indeed elsewhere in the body.

Finally, if manual skills are to be tested in the future as part of the structure of professional examinations for surgeons, why not do it properly and assess operating ability in the operating theatre during an operation? We can see no reason why this might be unacceptable to examiners, examinees, and patients. All medical schools rely on the cooperation of patients in final clinical examinations, as do the royal colleges in postgraduate examinations.

We consider the role of simulation in training of junior surgeons to be limited, and we deprecate any attempt to exclude surgeons in training from the environment of the operating theatre on whatever pretext.

B A TAYLOR

niversity of Liverpo

Liverpool L69 3BX

B J HARRISON

Royal Gwent Hospital,

Newport,

Gwent NP9 2UB

St George's Hospital,

London SW17 0QT

1 MacIntyre IMC, Munro A. Simulation in surgical training. Br.Med f 1990;300:1088-9. (28 April.)

SIR,-Although the editorial by Messrs I M C Macintyre and A Munro' fails to mention this, the importance of simulation models for surgical training has long been recognised by gynaecologists. For example, models such as the Pelvi-Trainer and practice protocols for operative laparoscopy have been developed by pioneers such as Semm, ${ }^{2}$ and with the growing interest in procedures such as laparoscopic cholecystectomy our general surgical colleagues will, no doubt, also use these devices.

Hysteroscopic transcervical resection of the endometrium shares many similarities with closed prostatectomy and thus urologists are a valued source of training and advice. None the less, the coordination and manipulation required to use a resectoscope are unnatural to most gynaecologists, even those accustomed to diagnostic hysteroscopy. In order to teach the use and feel of this instrument we have designed a simple, cheap training model to be used before operating. The model comprises an ordinary lidded plastic beaker $(125 \times 70 \times 50 \mathrm{~mm})$ with a $10 \mathrm{~mm}$ diameter hole positioned centrally in its base for inserting the resectoscope. Illumination is provided by either a cold light source fitted to the resectoscope, in which case the lid of the beaker can be closed, or an external light with the lid left open. A wide ridge of plasticine applied to the inside wall via the lid end simulates the endometrium, which can then be systematically "resected" without electrocautery using a cold cutting loop. Focal lesions such as polyps and fibroids can also be modelled easily with the plasticine and hysteroscopic "polypectomy" and "myomectomy" performed. After each resection it is a simple matter to 